\title{
Manfaat Media Flipchart dan Spanduk dalam Perilaku Kesehatan 1000 HPK di Sulawesi Tengah
}

\section{The Benefits of Flipchart Media and Banner Toward Health Behavior the First 1000 Days of Life in Central Sulawesi}

\author{
Nasrul $^{1}$, Zainul ${ }^{2}$, Fahmi Hafid ${ }^{3 *}$ Taqwin $^{4}$ \\ ${ }^{1,2}$ Jurusan Keperawatan Poltekkes Kemenkes Palu \\ ${ }^{3}$ Jurusan Gizi Poltekkes Kemenkes Palu \\ ${ }^{4}$ Jurusan Kebidanan Poltekkes Kemenkes Palu \\ (*hafid.fahmi79@gmail.com)
}

\begin{abstract}
ABSTRAK
Flipchart dan spanduk merupakan media komunikasi perubahan perilaku yang dapat meningkatkan efektivitas dari upaya program spesifik 1000 Hari Pertama Kehidupan (HPK). Penelitian bertujuan membuktikan manfaat media flipchart dan spanduk dalam perilaku kesehatan 1000 HPK di Sulawesi Tengah. Desain quasi eksperimen pretest and post test with control design yang terdiri tiga kelompok flipchart $(\mathrm{n}=32)$, spanduk $(\mathrm{n}=32)$ dan kontrol $(\mathrm{n}=31)$. Intervensi selama 6 bulan di Kabupaten Sigi, Touna dan Bangkep mulai 15 April hingga 28 Oktober 2016. Populasi penelitian adalah ibu yang memiliki anak umur 6-23 bulan. Sampel sebanyak 95 orang. Data dianalisis dengan uji chi-square, paired t test dan anova test. Hasil penelitian menunjukkan setelah intervensi 6 bulan terdapat peningkatan rerata perilaku $0,53 \pm 0,8$ pada kelompok I dengan intervensi flipchart dan peningkatan rerata perilaku $0.71 \pm 0,7$ pada kelompok II dengan intervensi spanduk. Peningkatan rerata perilaku antar kelompok I dengan intervensi flipchart, kelompok II dengan intervensi spanduk dan kontrol berbeda bermakna secara statistik $(p=0,002)$. Perilaku yang meningkat secara signifikan adalah perilaku menimbang anak secara teratur. Flipchart dan spanduk bermanfaat meningkatkan perilaku kesehatan 1000 HPK di Sulawesi Tengah.
\end{abstract}

Kata kunci : Flipchart, spanduk, 1000 HPK

\section{ABSTRACT}

Flipchart and banner are communications media in behavioral change that can improve the effectiveness of the specific program effort of the first 1000 days of life. This study aims to prove the benefits of Flipchart media and banners in health behavior of 1000 HPK in Central Sulawesi. The quasi-experimental design of pretest and post test with control design is consisted of three groups of flipchart $(n=32)$, banner $(n=32)$ and control $(n=31)$. The Intervention of study is held for 6 months in Sigi, Touna and Bangkep regencies from April 15 to October $28,2016$. The population is mothers with children aged 6-23 months with 95 people sample. The data were analyzed by chisquare, paired t test and anova test. The results showed that after 6 months intervention there was an increase in the mean behavior of $0.53 \pm 0.8$ in group I with the Flipchart intervention and the mean behavior improvement of $0.71 \pm 0.7$ in group II with banner intervention. Increased mean behavior of intergroup I with Flipchart intervention, group II with banner and control interventions was significantly different $(p=0,002)$. A significantly improved behavior is the regular weighing behavior of children. Flipcharts and beneficial banners improve the health behavior of the first 1000 days of life in Central Sulawesi.

Keywords : Flipchart, banner, The first 1,000 days 


\section{PENDAHULUAN}

Komunikasi Perubahan Perilaku (KPP) adalah komunikasi yang menggunakan berbagai media untuk memperbaiki perilaku khususnya perilaku kesehatan masyarakat. KPP merupakan pengembangan dari komunikasi informasi dan edukasi yang lebih menekankan pada perubahan perilaku, sehingga tidak hanya berhenti pada peningkatan pengetahuan dan sikap saja. ${ }^{1,2}$ Komunikasi perubahan perilaku adalah proses konsultatif berbasis penelitian yang menangani pengetahuan, sikap dan praktik. Metode partisipatif meliputi identifikasi, analisis, segmentasi peserta dengan menyediakan informasi relevan, motivasi secara interpersonal, kelompok dan media massa. ${ }^{3,4,5}$

Gerakan Scalling Up Nutrition bertujuan menurunkan masalah gizi dengan fokus pada 1000 hari pertama kehidupan (270 hari selama kehamilan dan 730 hari dari kelahiran sampai usia 2 tahun) yaitu pada ibu hamil, ibu menyusui dan anak usia 0-23 bulan. Gerakan Scalling Up Nutrition di Indonesia dikenal dengan gerakan nasional sadar gizi dalam rangka seribu hari pertama kehidupan disingkat Gerakan 1000 HPK. Untuk merumuskan gerakan 1000 HPK di Indonesia telah dilakukan serangkaian kegiatan yang melibatkan pemangku kepentingan utama dari kementerian dan lembaga, dunia usaha, mitra pembangunan internasional, lembaga sosial kemasyarakatan dan didukung oleh organisasi profesi, perguruan tinggi, serta media. Gerakan 1000 HPK terdiri dari intervensi spesifik dan intervensi gizi sensitif. Intervensi spesifik adalah tindakan atau kegiatan yang dalam perencanaannya ditujukan khusus untuk kelompok 1000 HPK. Kegiatan ini pada umumnya dilakukan oleh sektor kesehatan, seperti imunisasi, PMT ibu hamil dan balita, monitoring pertumbuhan balita di Posyandu, suplementasi tablet besi-folat ibu hamil, promosi ASI Eksklusif dan MP-ASI. Intervensi spesifik bersifat jangka pendek, hasilnya dapat dicatat dalam waktu relatif pendek. Intervensi sensitif adalah berbagai kegiatan pembangunan di luar sektor kesehatan. Sasarannya adalah masyarakat umum dan tidak hanya untuk 1000 HPK. $^{6}$

Data tahun 2013 menunjukkan masalah kesehatan di Sulawesi Tengah seperti risiko kekurangan energi kronik ibu hamil sebesar $32,6 \%$ berada diatas rata-rata nasional (24,2\%). Risiko tertinggi berada pada Kabupaten Banggai, Tojo Una-una,
Sigi. Demikian pula dengan balita pendek sebesar $41 \%$, lebih tinggi dari rerata nasional $(37,2 \%)$. Pemantauan status gizi melaporkan stunting balita sebesar di Sulawesi Tengah tahun 2015 sebesar 35,6\%. Kabupaten dengan prevalensi tertinggi berturut-turut adalah Kabupaten Sigi (45,2\%), Kabupaten Touna (42,3\%) dan Kabupaten Banggai $(40 \%)^{7}$

Penyebarluasan informasi tentang 1000 HPK diantaranya adalah pemanfaatan flipchart ibu hamil, ibu menyusui dan anak berumur 6-23 bulan. Flipchart ini dibuat dan didistribusikan oleh Kementerian Kesehatan. Flipchart lebih tepat digunakan untuk peserta individu di dalam ruangan, sementara untuk khalayak massa dan di luar ruangan penggunaan spanduk menjadi lebih tepat. Spanduk adalah cara yang efektif untuk menginformasikan, meyakinkan orang untuk memiliki perasaan dan semangat hidup yang baik. ${ }^{8}$ Penggunaan flipchart dan spanduk merupakan jembatan perubahan perilaku keluarga ibu baduta yang dapat menjadi pilihan untuk meningkatkan efektivitas dari upaya program spesifik 1000 HPK. Penelitian ini bertujuan membuktikan manfaat media flipchart dan spanduk dalam perilaku kesehatan 1000 HPK di Sulawesi Tengah.

\section{BAHAN DAN METODE}

Desain quasi eksperimen pretest and post test with control design. Responden dibagi menjadi 3 kelompok. Kelompok I intervensi dengan flipchart, kelompok II intervensi dengan spanduk, kelompok III sebagai kelompok kontrol. Pemilihan kelompok tidak melalui proses pengacakan, tetapi berdasarkan pertimbangan karakteristik wilayah dan disesuaikan dengan tujuan penelitian. Penelitian dilaksanakan selama 6 bulan mulai 15 April hingga 28 Oktober 2016 di Puskesmas Biromaru dan Pandere Kabupaten Sigi, Puskesmas Tombiano dan Uekuli Kabupaten Touna dan Puskesmas Salakan Kabupaten Bangkep. Populasi dalam penelitian ini adalah ibu dari anak 6-23 bulan di Kabupaten Sigi, Touna dan Banggai Kepulauan. Sampel penelitian sebanyak 95 orang.

Media flipchart dibuat oleh Kementerian Kesehatan. Konten media flipchart meliputi informasi detail tentang 1000 HPK, berukuran 41,5 x $30 \mathrm{~cm}$, terdiri dari 20 lembar 1000 hari pertama periode emas tumbuh kembang anak. Media flip- 
chart digunakan di posyandu dan puskesmas oleh tenaga kesehatan terlatih seperti Bidan, Perawat dan Ahli Gizi. Media spanduk dibuat oleh peneliti. Konten spanduk berisikan informasi pokok tentang 1000 HPK. Berukuran $150 \times 100 \mathrm{~cm}$ terdiri atas 2 tema utama yaitu; menimbang secara teratur dan memberikan MP-ASI tepat jumlah dan waktu. Spanduk dipasang di dinding puskesmas, posyandu, pagar puskesmas dan papan spanduk puskemas. Tulisan dalam spanduk terbaca dengan jarak pandang 30 meter. Pengumpulan data menggunakan enumerator yang telah dilatih, kuesioner yang telah diuji coba, layak etik penelitian dari Komisi Etik Penelitian Kesehatan Politeknik Kesehatan Kemenkes Yogyakarta dengan nomor LB.01.01/KE/XXXIX/367/2016. Uji yang digunakan adalah uji chi-square, paired t test dan anova test.

\section{HASIL}

Penelitian menunjukkan bahwa rata-rata ibu berumur 29,57 tahun dan ayah berumur 33,34 tahun. Ayah 45,9\% telah menamatkan pendidikan Sekolah Menengah Atas, 55,5\% ayah dan 8,5\% ibu bekerja sebagai petani/nelayan. Pekerjaan petani lebih banyak dijumpai pada kelompok II dengan intervensi spanduk yakni $64.8 \%$ dibanding kelompok I dengan intervensi flipchart (50,9\%). Jumlah anggota keluarga lebih dari 4 orang sebanyak $43.9 \%$. Pada kelompok I dengan intervensi flipchart lebih rendah yakni 39,2\% dibandingkan dengan kelompok II dengan intervensi spanduk yakni $46,3 \%$. Anak yang berjenis kelamin lakilaki sebanyak 57 orang $(60 \%)$. Rerata berat lahir $3139,0 \pm 417$ gram dan panjang badan $48,7 \pm 1,2 \mathrm{~cm}$. Gizi anak umur 6-23 bulan yang menjadi sampel dengan Z Score BB/TB $-0,4 \pm 1,4$. rerata Z Score $\mathrm{TB} / \mathrm{U}-1,6 \pm 1,6$ rerata Z-Score BB/U -1,2 $\pm 1,0$ (Tabel 1).

Sebelum intervensi perilaku menyusu $(\mathrm{p}=0,924)$ MP-ASI Seimbang dan Beragam $(\mathrm{p}=0,599)$ Suplementasi Vitamin A $(\mathrm{p}=0,092)$ dan

Tabel 1. Karakteristik Responden Penelitian Manfaat Media Flipchart dan Spanduk dalam Perilaku Kesehatan 1000 HPK

\begin{tabular}{|c|c|c|c|c|}
\hline \multirow[b]{2}{*}{ Variabel } & \multirow{2}{*}{$\begin{array}{c}\text { Kelompok } \\
\text { Kontrol } \\
(\mathbf{n}=\mathbf{3 1})\end{array}$} & \multicolumn{2}{|c|}{ Kelompok Intervensi } & \multirow{2}{*}{$\begin{array}{c}\text { Total }=95 \\
\text { n }(\%)\end{array}$} \\
\hline & & $\begin{array}{c}\text { Flipchart } \\
(\mathbf{n}=32)\end{array}$ & $\begin{array}{c}\text { Spanduk } \\
(\mathrm{n}=32)\end{array}$ & \\
\hline \multicolumn{5}{|l|}{ Karakteristik RT } \\
\hline Status Kepemilikan Rumah (pribadi) & $24(78.8)$ & $26(80.5)$ & $24(73.8)$ & $74(77,7)$ \\
\hline Tipe lantai rumah (tanah) & $15(48.8)$ & $12(36.5)$ & $16(48.8)$ & $42(44,7)$ \\
\hline Konstruksi rumah (kayu) & $11(36.9)$ & $15(46.2)$ & $12(36.9)$ & $38(40,0)$ \\
\hline Tipe toilet (WC Tertutup) & $19(62.4)$ & $23(70.4)$ & $20(62.4)$ & $62(65,1)$ \\
\hline Listrik (menyala selama 24 jam) & $23(75.8)$ & $24(75.6)$ & $25(78.8)$ & $73(76,7)$ \\
\hline \multicolumn{5}{|l|}{ Karakteristik Orang tua } \\
\hline Umur Ibu (tahun) & $28.06 \pm 7.2$ & $30.34 \pm 7.5$ & $30.25 \pm 7.5$ & $29.57 \pm 7,4$ \\
\hline Umur Ayah (tahun) & $32.23 \pm 9.1$ & $34.87 \pm 11,4$ & $32.94 \pm 7,6$ & $33.34 \pm 9,5$ \\
\hline Jumlah Anak & $2.7 \pm 1.7$ & $2.6 \pm 1.6$ & $2.7 \pm 1.7$ & $2,7 \pm 1,7$ \\
\hline Pendidikan Ibu ( $\geq$ Tamat SMA) & $14(44.5)$ & $11(35.2)$ & $14(44.5)$ & $39(41,4)$ \\
\hline Pendidikan Ayah ( $\geq$ Tamat SMA) & $15(48.8)$ & $13(40.1)$ & $16(48.8)$ & $44(45,9)$ \\
\hline Pekerjaan Ibu (Petani/nelayan) & $3(11.2)$ & $2(5.9)$ & $4(11.2)$ & $9(9,4)$ \\
\hline Pekerjaan Ayah (Petani/Nelayan) & $16(50,9)$ & $21(64.8)$ & $16(50,9)$ & $53(55,5)$ \\
\hline Jumlah anggota keluarga $>4$ orang & $14(46.3)$ & $13(39.2)$ & $15(46.3)$ & $42(43,9)$ \\
\hline Pengeluaran keluarga $(<1.670 .000)$ & $27(85.8)$ & $30(95.2)$ & $27(85.8)$ & $84(88,9)$ \\
\hline \multicolumn{5}{|l|}{ Karakteristik Anak } \\
\hline Jenis Kelamin (Laki-laki) & $18(31,6)$ & $19(33,3)$ & $20(35,1)$ & $57(60,0)$ \\
\hline Beral Lahir (gr) & $3125.0 \pm 395$ & $3118.5 \pm 336$ & $3172.4 \pm 509$ & $3139.0 \pm 417$ \\
\hline Panjang Badan Lahir (cm) & $48.4 \pm 0.9$ & $48.6 \pm 1.3$ & $49.2 \pm 1.3$ & $48.7 \pm 1.2$ \\
\hline Z Score BB/TB & $-0.01 \pm 1.0$ & $-0.7 \pm 1.3$ & $-0.6 \pm 1.7$ & $-0.4 \pm 1.4$ \\
\hline Z Score TB/U & $-2.2 \pm 1.2$ & $-1.7 \pm 1,7$ & $-1.0 \pm 1.8$ & $-1.6 \pm 1.6$ \\
\hline Z-Score BB/U & $-1.2 \pm 0,7$ & $-1.4 \pm 1,0$ & $-1.0 \pm 1.4$ & $-1.2 \pm 1.0$ \\
\hline
\end{tabular}

Sumber : Data Primer, 2016 
Tabel 2. Baseline Perilaku Kesehatan 1000 HPK Di Sulawesi Tengah

\begin{tabular}{|c|c|c|c|c|c|}
\hline \multirow[b]{2}{*}{ Variabel } & \multirow{2}{*}{$\begin{array}{c}\text { Kelompok } \\
\text { Kontrol } \\
(n=31)\end{array}$} & \multicolumn{2}{|c|}{ Kelompok Intervensi } & \multirow[b]{2}{*}{ Total } & \multirow[b]{2}{*}{ p-value } \\
\hline & & $\begin{array}{c}\text { Flipchart } \\
(n=32)\end{array}$ & $\begin{array}{c}\text { Spanduk } \\
(n=32)\end{array}$ & & \\
\hline Tetap Menyusui & $24(77,4)$ & $25(78,1)$ & $26(81,3)$ & $75(78,9)$ & 0,924 \\
\hline MP-ASI Seimbang dan Beragam & $21(67,7)$ & $22(68,8)$ & $25(78,1)$ & $68(71,6)$ & 0,599 \\
\hline Suplementasi Vitamin A & $22(71,0)$ & $26(81,3)$ & $18(56,3)$ & $66(69,5)$ & 0,092 \\
\hline Imunisasi Dasar & $12(38,7)$ & $22(68,8)$ & $22(68,8)$ & $56(58,9)$ & 0,020 \\
\hline Menimbang Secara Teratur & $21(67,7)$ & $23(71,9)$ & $26(81,3)$ & $70(73,7)$ & 0,458 \\
\hline
\end{tabular}

Sumber : Data primer ${ }^{1}$ Chi Square test

Tabel 3. Distribusi Perbedaan Rerata Praktik Perilaku Kesehatan 1000 HPK di Sulawesi Tengah

\begin{tabular}{lcccccc}
\hline \multirow{2}{*}{ Kelompok } & \multicolumn{2}{c}{ Perilaku Ibu Hamil } & & & \\
\cline { 2 - 3 } & & Sebelum & Sesudah & \multirow{2}{*}{ Mean diff. } & P1 & P2 \\
\cline { 2 - 3 } & Mean \pm SD & Mean \pm SD & & & 0,002 \\
\hline Kontrol $(\mathrm{n}=31)$ & $3.22 \pm 1.6$ & $3.29 \pm 1.4$ & $0.09 \pm 0,3$ & 0,161 & \\
Flipchart $(\mathrm{n}=32)$ & $3.68 \pm 1.7$ & $4.21 \pm 1.2$ & $0.53 \pm 0,8$ & 0,002 & \\
Spanduk $(\mathrm{n}=33)$ & $3.25 \pm 1,5$ & $4.37 \pm 1,0$ & $0.71 \pm 0,7$ & 0,000 & \\
\hline
\end{tabular}

Sumber : Data primer ${ }^{\mathrm{P} 1}$ Paired t test $;{ }^{\mathrm{P} 2}$ Anova test

perilaku menimbang secara teratur $(\mathrm{p}=0,458)$ tidak berbeda antar kelompok kecuali pada perilaku memberikan imunisasi dasar pada anak $(\mathrm{p}=0,020)$. Perilaku memberikan imunisasi dasar lebih tinggi pada kelompok I dengan intervensi flipchart dan kelompok II dengan intervesi spanduk dibanding kelompok kontrol (Tabel 2).

Komposit perilaku ibu dalam status tetap menyusui, memberikan MP-ASI seimbang dan beragam, suplementasi Vitamin A, imunisasi dasar dan menimbang anak secara teratur diberi point 5 jika semua perilaku tersebut dilaksanakan dan jika tidak dilaksanakan point 0 . Hasil penelitian menunjukkan sebelum intervensi rerata perilaku kesehatan tersebut pada kelompok kontrol $3,22 \pm 1,6$ kelompok I dengan intervensi flipchart $3,68 \pm 1,7$ dan kelompok II dengan intervensi spanduk 3,25 $\pm 1,5$. Tidak terdapat perbedaan komposit perilaku yang bermakna antar kelompok sebelum dilakukan intervensi $(p>0,05)$. Setelah intervensi 6 bulan ada peningkatan rerata komposit perilaku pada kelompok I dengan intervensi Flipchart $0,53 \pm 0,8$ dan kelompok II dengan intervensi spanduk $0.71 \pm 0,7$. Peningkatan rerata komposit peri-laku antar kelompok berbeda bermakna secara statistik $(\mathrm{p}=0,002)$. Perilaku yang meningkat secara signifikan adalah perilaku menimbang anak 6-23 bulan secara teratur (Tabel 3).

\section{PEMBAHASAN}

Strategi komunikasi berisi prinsip-prinsip dasar mengutamakan langkah-Iangkah praktis dalam melaksanakan kegiatannya. Kegiatan ini dapat dilaksanakan melalui berbagai media sesuai dengan situasi dan kondisi yang ada. Kegiatan yang efektif akan memberi hasil, yaitu penambahan pengetahuan dan perubahan perilaku pada sasaran. Penggunaan media dapat meningkatkan atensi, meningkatkan daya ingat/retensi terhadap suatu pesan/informasi dan untuk menjelaskan fakta-fakta, prosedur dan tindakan/keterampilan. Retensi adalah proses mengingat dan lupa terhadap sesuatu, untuk mencapai proporsi yang diingat agar cukup memadai, maka materi tersebut dengan media flipchart dan spanduk harus dibaca berulang-ulang dalam jangka waktu yang tidak terlalu lama.

Implementasi komunikasi perubahan perilaku memberi dampak peningkatan pengetahuan, sebagian besar orang tua anak mempraktikkan hasil intervensi dan menjadikan orang tua sebagai sebagai sumber informasi utama, untuk merekomendasikan dan mempromosikan praktik pemberian makan pada bayi dan anak. ${ }^{9}$ Selanjutnya dilaporkan bahwa komunikasi perubahan perilaku dapat meningkatkan perilaku ibu dalam perawatan post natal dan menyusui dini serta cakupan imunisasi. ${ }^{4}$

Menurut UNICEF, komunikasi yang efektif 
tergantung pada penggunaan 3 (tiga) aspek secara sinergis yaitu intervensi advokasi yang bertujuan untuk mempengaruhi kepemimpinan politik dan sosial untuk memastikan sumber daya dan dukungan untuk keberhasilan pelaksanaan program kesehatan. Mobilisasi sosial yang terlibat dan memotivasi berbagai mitra di tingkat nasional dan lokal untuk meningkatkan kesadaran dan tujuan tertentu. Pengembangan komunikasi perubahan perilaku sebagai proses partisipatif yang didasarkan pada penelitian formatif. Peserta dengan informasi yang relevan dan motivasi melalui strategi didefinisikan dengan baik, melibatkan pendekatan interpersonal, kelompok dan saluran media dan metode partisipatif. 5

Penelitian ini menunjukkan $78,1 \%$ orang tua memberikan makanan pendamping ASI seimbang dan beragam kepada anak pada usia yang disarankan, yakni usia enam bulan. Hasil ini didukung dengan beberapa studi yakni studi pada $200 \mathrm{ibu}-$ ibu di India selatan, ditemukan $77,5 \%$ dari orang tua anak usia kurang dua tahun telah memberikan makanan pendamping ASI sesuai waktu yang disarankan. ${ }^{10,11}$ Melalui survei dengan menggunakan sampel multistage cluster dari 10.000 rumah tangga menemukan prevalensi pengenalan makanan pendamping ASI sebanyak $92 \%$ pada usia 6-8 bulan. Namun demikian, pemberian makanan pendamping ASI yang seimbang dan beragam pada responden penelitian masih berada di bawah $80 \%$, hal ini menunjukkan kesadaran, pengetahuan masyarakat di lokasi penelitian masih kurang baik. Penelitian Chapagain, di Nepal menunjukkan bahwa lebih dari setengah responden $(56,81 \%)$ pemberian makanan pendamping ASI sudah tepat pada waktu yang disarankan. ${ }^{12}$

Tingginya tingkat inisiasi pemberian makanan pendamping ASI pada waktu yang disarankan di usia 6 bulan dalam penelitian ini berhubungan dengan tingkat kunjungan orang tua ke posyandu untuk menimbang yaitu $67,7-81,3 \%$. Hal lain yang mendukung hasil tersebut adalah mengingat penelitian ini berbasis masyarakat sehingga segala kegiatan yang terkait dengan kesehatan anak lebih banyak dilakukan di Posyandu. Penelitian ini menemukan bahwa $81,7 \%$ orang tua anak mendapat penyuluhan tentang pemberian makanan bagi bayi dan anak. Pemberian pertama kali makanan pendamping ASI berhubungan dengan pernah mendapat penyuluhan pemberian makanan pendamping pada bayi dan anak ( $\mathrm{p}=0,0001)$.

Pada variabel jumlah anggota rumah tangga yang makan sedapur dihubungkan dengan pemberian MP-ASI pertama kali pada penelitian ini didapatkan adanya hubungan bermakna $(\mathrm{p}=0.005)$. Terdapat $43,9 \%$ keluarga dengan jumlah anggota kurang dari empat orang yang makan sedapur memberikan makanan pendamping ASI pada waktu yang disarankan yaitu enam bulan atau lebih. Pekerjaan ibu pada penelitian ini tampak ada kecenderungan adanya hubungan meskipun secara statistik tidak didapatkan hubungan, pekerjaan sebagai ibu rumah tangga memberikan makanan pendamping ASI sesuai waktu yang disarankan $78,1 \%$. Hasil ini sejalan dengan temuan oleh Chapagain yang melaporkan bahwa pekerjaan sebagai ibu rumah tangga berhubungan erat dengan praktik pemberian makanan yang tepat. ${ }^{12}$

Hasil studi ini membuktikan bahwa intervensi flipchart dan spanduk perilaku program spesifik 1000 HPK dapat meningkatkan perilaku ibu tentang makanan pendamping ASI tepat waktu yang seimbang dan beragam. Tingkat pendidikan seseorang yang semakin tinggi akan berdampak pada perkembangan ke arah yang lebih baik sehingga ibu akan berpengetahuan yang baik, lebih objektif dan terbuka wawasanya dalam mengambil suatu keputusan atau tindakan yang diaplikasikan dengan perbuatan atau perilaku yang positif, terutama dalam hal memberikan makanan pendamping bagi anak. Pendidikan Ibu memainkan peran penting dalam meningkatkan penerimaan pengetahuan dan kesadaran yang berkaitan dengan kebutuhan gizi bayi dan anak.

Responden kelompok I dengan intervensi flipchart sebagian besar tinggal didaerah yang relatif lebih maju dibandingkan dengan masyarakat kelompok spanduk. Kondisi akses informasi yang lebih mudah serta fasilitas berupa kendaraan umum yang digunakan mudah diakses dibanding kelompok II dengan intervensi spanduk yang sebagian besar masih berjalan kaki menuju ke fasilitas kesehatan. Hasil penelitian di Tanzania menyatakan pengetahuan dan praktik pemberian makanan tambahan yang tidak sesuai di Tanzania pada anak usia 6-11 bulan disebabkan oleh terbatasnya akses terhadap media dan status ekonomi yang buruk serta pendidikan ayah atau 
ibu yang rendah ${ }^{11}$.

Pemerintah dalam hal ini dinas kesehatan dan puskesmas mengurangi risiko kesakitan dan kematian pada baduta akibat kekurangan vitamin A, dengan menyelenggarakan kegiatan pemberian vitamin A dalam bentuk pemberian kapsul vitamin A biru 100.000 IU bagi bayi usia 6 sampai dengan 11 bulan, dan pemberian kapsul vitamin A merah 200.000 IU untuk anak baduta usia 12 sampai dengan 59 bulan. ${ }^{13}$ Telah diketahui bahwa kekurangan vitamin A dapat menurunkan fungsi kekebalan tubuh sehingga dapat meningkatkan terjadinya morbiditas dan mortalitas dari beberapa penyakit infeksi seperti diare, infeksi saluran pernapasan bawah, dan campak. Peranan vitamin A adalah membentuk respon imun melalui peningkatan respon imun sel $\mathrm{T}$ dan retinol yang berpengaruh terhadap pertumbuhan dan diferensiasi limfosit B. Suplemen Vitamin A telah digunakan untuk mencegah atau mengobati kekurangan vitamin A dan menurunkan mortalitas dan morbiditas pada anak-anak. ${ }^{14}$

Hasil penelitian menunjukkan perilaku pemberian suplementasi Vitamin A tertinggi pada kelompok I dengan intervensi flipchart sebesar $81,3 \%$ kemudian kelompok kontrol $71,0 \%$ dan terakhir kelompok II dengan intervensi spanduk $56,3 \%$, sedangkan perilaku menimbang anak secara teratur tertinggi pada kelompok II dengan intervensi spanduk 81,3\% kemudian kelompok I dengan intervensi flipchart $71,9 \%$ terendah kelompok kontrol $67,7 \%$. Kegiatan pemberian vitamin A dilaksanakan pada bulan Februari dan Agustus. Oleh karena penelitian hanya dilaksanakan 2 bulan maka pemberian suplemen Vitamin A yang terekam oleh kegiatan penelitian hanya pada bulan Agustus saja dan tidak dapat mencatat perilaku untuk bulan Februari tahun 2017. Oleh karena itu, salah satu kekurangan penelitian ini adalah waktu yang singkat yang tidak dapat merekam perilaku yang hanya diamati 6 bulan kemudian.

Imunisasi adalah suatu cara untuk menimbulkan/meningkatkan kekebalan seseorang secara aktif terhadap suatu penyakit, sehingga bila kelak terpapar dengan penyakit tersebut tidak akan menderita penyakit tersebut. Imunisasi dasar adalah pemberian imunisasi awal untuk mencapai kadar kekebalan di atas ambang perlindungan. Imunisasi lanjutan adalah imunisasi ulangan untuk mempertahankan tingkat kekebalan di atas ambang perlindungan atau untuk memperpanjang masa perlindungan. ${ }^{15}$ Imunisasi hepatitis B-0 adalah imunisasi yang diberikan sesaat setelah bayi lahir sampai bayi berusia 7 hari yang disuntikkan di paha bayi. Imunisasi BCG adalah imunisasi yang mulai diberikan usia 1 hari dan disuntikkan di lengan atas atau paha serta meninggalkan bekas/scar di bawah kulit. Imunisasi DPT-HB Combo adalah imunisasi yang disuntikkan di paha dan biasanya mulai diberikan pada saat anak berusia 2 bulan bersama dengan polio sebanyak tiga kali. Imunisasi polio adalah imunisasi cairan merah muda atau putih yang biasanya mulai diberikan pada usia 2 bulan sebanyak 4x dan diteteskan ke mulut. Imunisasi campak adalah imunisasi yang biasanya mulai diberikan pada usia 9 bulan dan disuntikkan di paha serta diberikan satu kali. ${ }^{16}$

Hasil penelitian menunjukkan bahwa pada kelompok kontrol perilaku memberikan imunisasi dasar masih sangat rendah yaitu hanya $38,7 \%$. Perilaku memberikan imunisasi dasar pada kelompok I dengan intervensi flipchart dan kelompok II dengan intervensi spanduk sudah cukup baik yaitu $68,8 \%$. Namun demikian, hal tersebut masih di bawah cakupan yang diharapkan. Hasil analisis Martianto dkk menunjukkan bahwa faktor yang menyebabkan disparitas prevalensi stunting antara lain imunisasi yang tidak lengkap. ${ }^{17}$ Kejadian stunting pada anak baduta dengan imunisasi dasar yang tidak lengkap $(54,8 \%)$ lebih besar dibanding kejadian stunting pada anak dengan imunisasi yang lengkap (38,9\%). Kejadian stunting pada usia 6-23 bulan memiliki hubungan yang signifikan dengan kelengkapan imunsasi dasar $(\mathrm{p}<0.05) .{ }^{18}$

Perilaku menimbang anak yang diperoleh dari hasil penelitian menunjukkan bahwa perilaku ini pada kelompok kontrol $(67,7 \%)$ lebih rendah dibanding kelompok I dengan intervensi flipchart $(71,9 \%)$ dan kelompok II intervensi dengan spanduk (81,3\%). Pada akhir post intervensi perilaku ini yang nampak paling signifikan mengalami peningkatan. Komunikasi perubahan perilaku bertujuan mengubah pengetahuan, mengubah sikap dan praktik serta menanamkan perilaku baru yang dilaksanakan secara terencana dengan menggunakan media. Penelitian di Bangladesh menyatakan bahwa Intervensi komunikasi perubahan perilaku yang dilakukan secara konsisten dapat meningkatkan pengetahuan yang baik ten- 
tang praktik pemberian makanan pada bayi dan anak. ${ }^{9}$ Selain itu, penelitian Mbuya et.al., di Haiti melaporkan bahwa komunikasi perubahan perilaku meningkatkan pengetahuan ibu dan kader kesehatan tentang informasi gizi. ${ }^{19}$

Penggunaan flipchart dan spanduk berisi prinsip dasar yang mengutamakan langkahlangkah praktis dalam melaksanakan kegiatan 1000 HPK. Penggunaan spanduk untuk menarik minat masyarakat, pesan lebih bersifat terbatas dapat diakses oleh khalayak individu, kelompok kecil atau massa, respon bersifat balik segera atau tertunda. Oleh karena, media spanduk cukup tepat digunakan untuk mensosialisasikan kegiatan 1000 HPK. Ketertarikan atas informasi yang terpampang di spanduk dapat ditindaklanjuti dengan penyuluhan atau konseling dengan menggunakan media flipchart 1000 HPK.

Beberapa hasil penelitian serupa yang mendukung hasil ini yakni intervensi dengan menggunakan media sepeti pelatihan lokakarya, klinik kesehatan, flipchart dan poster kesehatan dapat meningkatkan pengetahuan penggunaan makanan lokal untuk kesehatan. ${ }^{20}$ Sejalan dengan hal tersebut, penyuluhan dengan menggunakan flipchart dan poster dapat meningkatkan pengetahuan, sikap dan praktik ibu dalam pemberian makan pada anak balita. ${ }^{21}$ Pendidikan merupakan salah satu strategi perubahan perilaku. Melalui upaya pendidikan dan penyuluhan bertujuan agar pengetahuan dapat meningkat. Peningkatan pengetahuan, bertujuan agar ibu dapat memahami pentingnya perilaku kesehatan terkait dengan program spesifik 1000 HPK. ${ }^{2}$

Praktik ibu dalam pemberian MP-ASI dan penimbangan teratur pada penelitian ini secara keseluruhan menujukkan praktik yang positif pada kelompok I dengan intervensi spanduk. Hasil ini terkait dengan tingginya tingkat kunjungan responden ke posyandu untuk mendapatkan informasi tentang pemberian makanan bayi dan anak (PMBA) pada kelompok ini. Responden mendapat informasi dari tenaga kesehatan dan kader di posyandu sehingga dapat membentuk sikap yang baik pada responden. Sikap dan perilaku tokoh masyarakat dan petugas kesehatan serta keluarga merupakan faktor penguat terjadinya perubahan perilaku seseorang. ${ }^{8}$

Selain itu, pemberian intervensi dilakukan tanpa dibarengi dengan kesiapan petugas dan kondisi lingkungan yang mendukung, menyebabkan informasi yang disampaikan petugas tidak dapat diterima dan dipahami dengan baik oleh responden. Hal ini sejalan dengan hasil temuan Snyder, yang melaporkan bahwa kegiatan komunikasi gizi dengan memperhatikan tujuan intervensi, isi pesan, media, dan teknik penyampaian adalah faktor yang mempengaruhi tingkat keberhasilan perubahan perilaku gizi. ${ }^{22}$ Hasil tersebut sesuai dengan yang dikemukakan oleh Kalita, bahwa komunikasi perubahan perilaku dapat memahami situasi masyarakat dengan menggunakan proses komunikasi dan media untuk mempengaruhi orang lain untuk meningkatkan pengetahuan dan mengubah perilaku dan praktik yang menempatkan mereka pada risiko. ${ }^{23}$

Flipchart dan spanduk sebagai alat komunikasi merupakan strategi komunikasi untuk mengadopsi perilaku positif yang sesuai dengan masalah lokal, norma dan aturan yang ada. Manfaat flipchart dan spanduk pada program spesifik 1000 HPK merupakan bukti dan proses berbasis penelitian yang menggunakan media komunikasi untuk mempromosikan perilaku yang mengarah pada peningkatan hasil kesehatan. Perubahan perilaku seseorang dapat dipengaruhi oleh komunikasi, Sarker et al, menemukan hubungan yang signifikan antara paparan pendekatan komunikasi dengan perubahan perilaku (iklan TV, poster, flipchart dan stiker) dengan skor pengetahuan $(\mathrm{p}<0.05){ }^{24}$

Laporan hasil penelitian diatas senada dengan laporan dari Fabrizio, yang menegaskan bahwa komunikasi perubahan perilaku memiliki peran penting dalam meningkatkan makanan bergizi dan perawatan praktik, dan pada gilirannya, meningkatkan pertumbuhan dan mencegah stunting. ${ }^{25}$

\section{KESIMPULAN DAN SARAN}

Flipchart dan spanduk bermanfaat meningkatkan perilaku kesehatan 1000 HPK di Sulawesi Tengah. Setelah intervensi 6 bulan terdapat peningkatan rerata perilaku $0,53 \pm 0,8$ pada kelompok I dengan intervensi Flipchart dan peningkatan rerata perilaku $0.71 \pm 0,7$ pada kelompok II dengan intervensi spanduk. Peningkatan rerata perilaku antar kelompok I dengan intervensi flipchart, 
kelompok II dengan intervensi spanduk dan kontrol berbeda bermakna secara statistik $(\mathrm{p}=0,002)$. Perilaku yang meningkat secara signifikan adalah perilaku menimbang anak secara teratur. Peneliti menyarankan agar dinas kesehatan memanfaatkan flipchart dan spanduk 1000 HPK ke dalam program puskesmas dan bidang promosi kesehatan. Penelitian lebih lanjut dengan metode yang bervariasi dan intrumen yang lebih sempurna perlu dilakukan agar tujuan program 1000 HPK dapat tercapai.

\section{UCAPAN TERIMA KASIH}

Ucapan terima kasih kepada Direktur Poltekkes Kemenkes Palu dan Kepala Badan PPSDM Kesehatan Kementerian Kesehatan atas dukungan dana dan kesempatan penelitian melalui Risbinakes Dosen Poltekkes tahun 2016.

\section{DAFTAR PUSTAKA}

1. Baquero B, Ayala GX, Arredondo, et al. Processes of Dietary Change Via a Tailored Nutrition Communication Intervention for Latinas. Health Educ Res. 2009;24:855-66.

2. Mahdali IM, Indriasari R, Thaha, R. Efek Edukasi Gizi terhadap Pengetahuan, Sikap serta Perubahan Perilaku Remaja Obesitas di Kota Gorontalo [diakses tanggal 18 Oktober 2017]. Available at : http://pasca.unhas.ac.id/jurnal/ files/996fbd1 ba790a572680d1592f0eaf3e5. pdf.

3. CuziatG \& Mattinen H. Maximising the Nutritional Impact of security and Livelihoods Intervention A Manual for field workers, London; AFC International. 2011.

4. Damstadt, G. L. \& Kiran, T. U. Behavior Change Communication as an Intervention to Improve Family Health Outcomes. Journal of Family Welfare. 2010;56.

5. Suresh. Evidence Based Communication for Health Promotion Indian Lessons of Last Decade. Indian J Public Health. 2011;55(4):27685.

6. Bappenas. Kerangka Kebijakan Gerakan Sadar Gizi dalam Rangka Seribu Hari Pertama Kehidupan (1000 HPK). Jakarta: Bappenas; 2012

7. Dinas Kesehatan Provinsi Sulawesi Tengah, Pemantauan Status Gizi di Sulawesi Tengah.
Palu: Dinas Kesehatan Provinsi Sulawesi Tengah; 2015.

8. Suwarno. IH. Wajah Spanduk Solidaritas Gempa Yogyakarta: Tinjauan dari Perspektif Komunikasi. Jurnal Ilmu Sosial dan Ilmu Politik. Komunikasi Bencana. 2008;11(3): 331-356.

9. Avula, R., Menon, P., Saha, K. K., Bhuiyan, et al. A Program Impact Pathway Analysis Identifies Critical Steps in the Implementation and Utilization of a Behavior Change Communication Intervention Promoting Infant and Child Feeding Practices in Bangladesh. The Journal of nutrition. 2013;143:2029-2037.

10. Rao S, Swathi PM, Unnikrishnan B, Hegde A. Study of Complementary Feeding Practices among Mothers of Children Aged Six Months to Two Years-A study from Coastal South India. Australasian Medical Journal. 2011;4, 252-257.

11. Victor, R, Baines, SK, Agho, K. E. \& Dibley, M. J. Factors Associated with Inappropriate Complementary Feeding Practices among Children Aged 6-23 Months in Tanzania. Maternal \& childnutrition. 2012;10(4).

12. Chapagain R.H. Factors Affecting Complementary Feeding Practices of Nepali Mothers for 6 Months to 24 Months Children. J Nepal Health Res Counc. 2013;11(24):205-7

13. Permenkes RI Nomor 21 Tahun 2015. Tentang Standar Kapsul Vitamin A Bagi Bayi, Anak Balita, dan Ibu Nifas. Jakarta: Kementerian Kesehatan Jakarta.

14. Peniche MT, Issues and Controversies with Vitamin A in Childhood, Nestlé Nutrition Institute Workshop Series 2012;70:91-102

15. Kementerian Kesehatan, 2005, Kepmenkes RI No 1611/Menkes/SK/XI/2005

16. Nadiyah, Faktor Risiko Stunting Pada Anak Usia 0-23 Bulan Di Provinsi Bali, Jawa Barat Dan Nusa Tenggara Timur [Tesis]. Bogor: Sekolah Pascasarjana Institut Pertanian Bogor; 2013.

17. Martianto, Syarief, Heryatno, Tanziha Yuliana. Analisis Disparitas Prevalensi Stunting Balita Berbagai Wilayah Indonesia Serta Implikasinya Kebijakan, Prosiding Seminar Hasil-Hasil PPM IPB. Bogor; 2013.

18. Nasrul, Hafid, F, AR.Thaha, Suriah. Faktor 
Risiko Stunting Anak Usia 6-23 Bulan Di Kecamatan Bontoramba Kabupaten Jeneponto, Media Kesehatan Masyarakat Indonesia. 2015;11(3):139-146

19. Mbuya, MN, Menon P, Habicht J P, Pelto GH, \& Ruel MT. Maternal Knowledge after Nutrition Behavior Change Communication is Conditional on Both Health Workers' Knowledge and Knowledge-Sharing Efficacy in Rural Haiti. J Nutr. 2013;143:2022-8.

20. Corsi A, Eng L, Flores R, Lorens A, \& Fitzgeral HM. A Participatory Assessment Of Dietary Patterns And Food Behaviour In Ponpei Federated States Of Micronesia. Asia Pac J. Clin Nutr, 2008; 209.

21. Guldan, GS, Fan HC, Ma X, Ni Z, Xiang X \& Tang MZ. Culturally Appropriate Nutrition Education Improves Infant Feeding and Growth in Rural Sichuan, China. The Journal of Nutrition. 2000; 130:1204-1211.
22. Snyder LB. Health Communication Campaigns and their Impact on Behavior. Journal of Nutrition Education and Behavior. 2007;39:S32-S40.

23. Kalita, A. Maternal Behaviour Change for Child Health and Nutrition. Social Initiatives Group 2006, ICIC Bank, Mumbai, India.

24. Sarker BK, Mridha MK, Dasgupta, SK, Islam N\& Reichenbach L. The effect of Behavior Change Communication (BCC) Interventions on Maternal Neonatal and Child Health $(\mathrm{MNCH})$ Knowledge in Urban Slums of Bangladesh [working paper]. 2012; Manoshi Working Paper.

25. Fabrizio CS, LiereM \& PeltoG. Identifying Determinants of Effective Complementary Feeding Behaviour Change Interventions in Developing Countries. Maternal \& Child Nutrition. 2014; 10(4):575-92. 